\title{
Performance of Laterite Soil Grains as Adsorbent in the Removal of Chromium
}

\author{
I.J. SYAMA ${ }^{1}$, ARUN KUMAR THALLA ${ }^{2}$ and D.S. MANU ${ }^{3 *}$ \\ Department of Civil Engineering, National Institute of Technology Karnataka, \\ Surathkal, Karnataka, India.
}

http://dx.doi.org/10.12944/CWE.10.1.33

(Received: January 16, 2015; Accepted: February 20, 2015)

\begin{abstract}
The present study aims to examine the efficiency of laterite grains (LG) and acid activated laterite grains (AALG) as an adsorbent for removal hexavalent chromium and ferric ion from synthetic wastewater, under laboratory conditions. Adsorption of hexavalent chromium and ferric ion from synthetic wastewater is examined by batch and column studies wherein it is found to be dependent on $\mathrm{pH}$, Contact time, adsorbent dosage and initial adsorbate concentration. Percentage removal enhances with the increase in adsorbent dosage and with low $\mathrm{pH}$, the optimal removal is achieved at $\mathrm{pH}=2$. AALG is found to investigate possibility of improvement in removal efficiency of hexavalent chromium. The removal efficiency of AALG is found to be significantly higher than the efficiency obtained from $L G$, at $\mathrm{pH}=7$. An adsorbent dosage $2 \mathrm{~g}$ of $\mathrm{LG}$ is found to be optimum for removal of ferric ion with low initial concentration of $2.5 \mathrm{mg} / \mathrm{L}$. The equilibrium adsorption data obtained from batch studies were fitted with Langmuir and freundlich isotherm for both hexavalent chromium and ferric ions. The percentage removal obtained from batch adsorption studies were found to be higher than that obtained by column studies for both the adsorbates.
\end{abstract}

Key words: Adsorption, Laterite, Chromium, Isotherms.

\section{INTRODUCTION}

Since last 5 decades, environmental pollution due to rapid industrialization has created more modern problems. Industries have a large prospective to cause streams, river, lake and sea pollution, thereby causing increased addition of heavy metals into the environment (Sahu et al. 2009). Environment pollution by toxic heavy metals occurs through industrial, military and agricultural processes (Ajmal, Ali Khan Rao, and Siddiqui 1996).A serious threat that posed to the environment due to the discharge of heavy metals into the streams there by causing accumulation leading to adulteration of food chain . Toxicity is caused due to the presence of heavy metals like $\mathrm{Ni}, \mathrm{Zn}, \mathrm{Cu}, \mathrm{Cd}, \mathrm{Cr}$, and $\mathrm{Hg}$ are toxic even in trace amounts. Metal species produced due to the various activities, when released into the environment they increase persistently (Chand, Agarwal, and Kumar 1994). It is a mandate to monitor their levels within permissible limits as recommended by the World Health Organization (WHO) in drinking water, wastewater and water used for farming and recreational uses.

$\mathrm{Cr}(\mathrm{VI})$ and $\mathrm{Cr}$ (III) are the two stable oxidation states of chromium. The $\mathrm{Cr}(\mathrm{VI})$ state is of especial interest because of its noxious. Thermodynamically stable chromate $\left(\mathrm{CrO}_{4}{ }^{2-}\right)$ and dichromate $\left(\mathrm{Cr}_{2} \mathrm{O}_{7}^{2-}\right)$ anions which vary over a wide $\mathrm{pH}$ range are the usual hexavalent chromium wastes discharged into the surroundings. $\mathrm{Cr}(\mathrm{VI})$ compounds are noxious which causes lung cancer, as well as kidney, liver and skin damage in human beings (Kousalya, Gandhi, and Meenakshi 2010). As per Indian standards the acceptable limit of $\mathrm{Cr}(\mathrm{VI})$ that is to be discharged from industrial effluents to surface water is $0.1 \mathrm{mglL}$. The maximum acceptable limit of the chromium content in drinking water is 0.05 $\mathrm{mg} / \mathrm{L}$. Various treatment skills have been developed 
for removal of organics and toxic heavy metals from both domestic and industrial wastewater (Mohan and Singh 2002). The widely used physico-chemical techniques to treat wastewater includes adsorption, ion-exchange, electrodialysis, chemical reaction, filtration, coagulation/flocculation, reverse osmosis etc. (Sahu et al. 2009) (Owlad et al. 2008). Choice of reliable treatment method depends upon effluent characteristics such as flow rate, $\mathrm{pH}$, temperature, heavy metals, and trace organics. Physico-chemical processes are found to be more advantageous compared to biological processes. Physico-chemical treatment processes remain unaffected even in the presence of toxic wastes such as heavy metals, however, biological treatment processes fail to function in case of wastes such as inorganic or nonbiodegradable in nature.

The present study aims to examine the adsorption characteristics of $L G$ intended to be used as an adsorbent for removal chromium size ranging from $0.6 \mathrm{~mm}$ to $1.18 \mathrm{~mm}$ in synthetic wastewater treatment. In general laterite is red colored, highly weathered acidic soil, rich in sesquioxides, iron oxide and alumina and possesses low cation exchange capacity due its weathered nature (Maji, Pal, and Pal 2008). LG was found to be a suitable low cost adsorbent for arsenic and fluoride removal by many researchers (Maiti et al. 2013), (Srinivasa Rao, Anand, and Venkateswarlu 2010)(Sanjoy Kumar Maji et al. 2007), (Sarkar et al. 2006). However, it was found that, as soil particle size decreases adsorption efficiency increases. Small size particles at the times creates operational difficulties, for e.g., (Sarkar et al. 2006) separation of finer laterite particles by filtration during batch operation, choking of laterite bed during column operation (Sarkar et al. 2006). Limited studies have been carried out on the adsorption performance of $L G$ of particle size ranging from 0.5 $\mathrm{mm}$ to $10 \mathrm{~mm}$.

\section{MATERIALS AND METHODS}

\section{Adsorbent preparation}

\section{Raw Laterite grain Preparation (LG)}

LG were collected from the Surathkal region of Karnataka. The collected grains were washed several times with tap water to remove undesirable layers like decayed organic matter, worm, sand, dust etc. Then the sample was air dried for 2- 3 days. A part of air dried sample was crushed to get soil of particle size less than $425 \mu$, for conducting soil characterization studies. The soil thus obtained was washed 20-30 times to remove red color of iron and finally air dried for 2-3 days and kept in an air tight container to avoid further moisture absorption. (Sanjoy K Maji, Pal, and Pal 2007).

\section{Acid Activated laterite preparation}

Adsorption studies of $\mathrm{Cr}(\mathrm{VI})$ were done also on AALG soil. $50 \mathrm{~g}$ of raw laterite $(\mathrm{RL})$ prepared with average size of particle $0.6-1.18 \mathrm{~mm}$ and $100 \mathrm{~mL}$ of $0.2 \mathrm{~N} \mathrm{Hcl}$ solution were taken into 250 $\mathrm{mL}$ glass beaker. The acid-laterite mixtures were mechanically agitated at 300 RPM for 2.0 hours. The mixture was kept further at room temperature for 24 hours. The solid fraction was taken in a beaker and washed with distilled water. Washing was performed until the $\mathrm{pH}$ of the wash water reached about 6.5. Finally, AAL was sun dried and screened to get desired size fractions between 0.6 and $1.18 \mathrm{~mm}$ (Maiti, Basu, and De 2010)

\section{Soil characterisation tests}

In order to characterize the soil with respect to parameters relevant to adsorption chemical analysis of the soil sample prepared were done as per standard methods (APHA, 2005). The RL and AAL soil samples were characterized for percentage silica content, alumina content, iron oxide content, organic matter content, carbonate content and $\mathrm{pH}_{\mathrm{zPC}}$. Table 1. gives the soil characterization methods adopted for chemical analysis of soil.

\section{ADSORBATE PREPARATION}

For the study, synthetically prepared metal solutions were used for evaluating the adsorption efficiency of the LG. For both ferric and hexavalent chromium ions, the adsorbate solution were prepared as explained in below sections.

\section{Ferric Ion Solution}

Stock ferrous ion (Fe (III)) solution of $100 \mathrm{mg} / \mathrm{L}$ was prepared from ferrous ammonium sulphate $\left(\mathrm{Fe}\left(\mathrm{NH}_{4}\right)_{2}\left(\mathrm{SO}_{4}\right)_{2} \cdot 6 \mathrm{H}_{2} \mathrm{O}\right)$. Initially $20 \mathrm{ml}$ of concentrated sulphuric acid was transferred into 50 $\mathrm{ml}$ of deionized water and about $1.404 \mathrm{~g}$ of ferrous ammonium sulphate was dissolved into it. Then it was subjected to drop wise treatment using $0.1 \mathrm{~N}$ $\mathrm{KMnO}_{4}$ until a faint pink color persists. Addition of 
excess $\mathrm{KMnO}_{4}$ to the ferrous ammonium sulphate solution ensures the complete oxidation of ferrous ion to ferric ion. Since the prepared ferric ion solution is acidic in nature, ferric ion exists in dissolved form in the same. The solution was then diluted to $1000 \mathrm{ml}$ for producing iron solution of $100 \mathrm{mg} / \mathrm{L}$. From the stock solution, the ferric ion solutions of required concentrations were prepared via dilution using deionized water.

\section{Hexavalent Chromium Solution}

About $282.8 \mathrm{mg}$ of potassium dichromate $\left(\mathrm{K}_{2} \mathrm{Cr}_{2} \mathrm{O}_{7}\right)$ was dissolved in $100 \mathrm{ml}$ distilled water to give a chromium ( $\mathrm{Cr}(\mathrm{VI}))$ concentration of 500 $\mathrm{mg} / \mathrm{L}$. From this, $\mathrm{Cr}(\mathrm{VI})$ ion solutions of required concentrations were prepared via dilution with deionized water.

\section{Adsorbate analysis}

For the analysis of ferric ion, PC Spectro - Lovibond and for hexavalent chromium analysis double beam spectrophotometer was used as shown in Table 2.

\section{Adsorption studies methodology Batch study}

Adsorption batch studies were performed to study the adsorption behavior of laterite grains in batch mode. Batch studies aim to develop adsorption isotherms, and study the effect of $\mathrm{pH}$, adsorbate concentration, adsorbent dosage, and contact time on adsorbate removal.

For each trial $25 \mathrm{ml}$ of hexavalent chromium and $60 \mathrm{ml}$ of ferric ion was prepared from the stock solution of known concentration and $\mathrm{pH}$ with a desired laterite dosage. It was taken into a $300 \mathrm{ml}$ BOD bottle, placed into the flash mixer and agitated at a fixed speed of $220 \mathrm{rpm}$ for the required contact time. All the trials were carried out using deionized water. $0.1 \mathrm{~N} \mathrm{NaOH}$ and $0.1 \mathrm{~N} \mathrm{H}_{2} \mathrm{SO}_{4}$ were used for adjusting the initial $\mathrm{pH}$ of the adsorbate solution to the desired value. After the required contact time the solution was filtered through filter paper and analyzed for adsorbate concentration. The percentage removal of the adsorbate and adsorption capacity of adsorbent was calculated using the Equ.1 as given below.

$$
\text { Percentage removal }=\frac{\left(C_{0}-C_{f}\right)}{c_{0}} \times 100
$$

Where, $C_{0}=$ Initial concentration of adsorbate (mg/L)

$C_{f}=$ final concentration of adsorbate $(\mathrm{mg} / \mathrm{L})$

Table 1: Soil Characterization Methodology

\begin{tabular}{|c|c|c|c|}
\hline $\begin{array}{l}\text { SI. } \\
\text { No }\end{array}$ & $\begin{array}{l}\text { Characteristics } \\
\text { of soil }\end{array}$ & Method & References \\
\hline 1 & Silica (\%) & Gravimetric & $\begin{array}{l}\text { IS:2720(Part 25) - } 1982 \text { (Soil Engineering and } \\
\text { Rock Mechanics Sectional Committee 1982) }\end{array}$ \\
\hline 2 & Alumina ( \%) & Gravimetric & \\
\hline 3 & Iron oxide (\%) & Thiocynate method & (Wagner, Clever, and Peters 1947) \\
\hline 4 & Organic matter content & Titration method & $\begin{array}{l}\text { IS:2720 (Part22) - } 1972 \text { section 1. (Soil } \\
\text { Engineering Sectional Committee 1972) }\end{array}$ \\
\hline 5 & Carbonate content & Titration method & (Rowell 1994) \\
\hline 6 & $\mathrm{pH}_{\mathrm{ZPC}}$ & Mass titration method & (Reymond and Kolenda 1999) \\
\hline
\end{tabular}

Table 2: Adsorbate Analysis Methodology

\begin{tabular}{lll}
\hline Metal Ion Analysis & Standard Method/ Procedure & Reference \\
\hline Ferric lon Analysis & $\begin{array}{l}\text { Evaluation of Ferric Thiocyanate colorimetric } \\
\text { method }\end{array}$ & (Wagner et al. 1947) \\
Hexavalent Chromium & $\begin{array}{l}\text { Determination of Hexavalent Chromium } \\
\text { (colorimetric method) }\end{array}$ & (United States Environment \\
Analysis & Protection Agency 2004) \\
\hline
\end{tabular}




\section{Column study}

Fixed bed column studies were conducted to study the adsorption of Fe (III) and $\mathrm{Cr}(\mathrm{VI})$ ions on laterite soil grains during continuous flow passages. The experiments were carried on a glass column of $2.5 \mathrm{~cm}$ diameter and over $50 \mathrm{~cm}$ total height. The column was packed with the adsorbent over a height of $30 \mathrm{~cm}$ between two supporting layers of glass wool as shown in Figure.1

The glass wool used did not take part in the adsorption process, but instead it is used to ensure proper positioning of laterite layer and afforded a uniform down the flow of the absorbate solution onto the adsorbent. For maintaining the flow rate through the sample, instead of using an inlet feed pump, the metal solution was provided in a container placed at a suitable height. The metal solution passed through the column by gravity.

For all adsorption experiments the column height was maintained as $30 \mathrm{~cm}$ and flow rate was maintained to be $5 \mathrm{ml} / \mathrm{min}$. In order to study the effect of initial adsorbate concentration upon adsorption, column study was conducted for two different initial metal ion concentrations. For chromium studies were conducted for an initial adsorbate concentration of $5 \mathrm{mg} / \mathrm{l}$, and $10 \mathrm{mg} / \mathrm{l}$ and for ferric ions column behavior at $2.5 \mathrm{mg} / \mathrm{l}$ was studied. To determine the extent of adsorption, samples were taken from the adsorption column at specific time intervals, from the bottommost outlet. The samples taken were then analyzed to assess the residual amount of $\mathrm{Cr}(\mathrm{VI})$ or Fe (III) present in it. The entire column experiment was conducted over a suitable period of time until the effluent concentration for the bottommost outlet reached $80 \%$ of the influent concentration. For a particular adsorbate, all adsorption experiments were done on the same adsorbent column (without adsorbent being replaced). After each adsorption experiment, the adsorbent was suitably down, washed with copious amounts of deionized water for a suitable time period.

\section{RESULTS AND DISCUSSION}

This section discusses the results of soil characterization tests, batch and column studies of hexavalent chromium and ferric ions on $L G$ and AALG.

\section{Soil characterisation tests results}

Results of soil characterization tests conducted on LG and AALG as shown inTable.3.

AALG resulted in the decrease of iron oxide, alumina, organic carbon, carbonate content and $\mathrm{pH}_{\mathrm{ZPC}}$ of LG. All these changes can lead to the increased pore volume and specific surface area of the AALG soil particles which in-turn could increase the adsorption capacity in comparison to raw laterite grains.

\section{Adsorption Studies on Hexavalent Chromium on LG and AALG}

In order to increase the removal efficiency and to formulate adsorption isotherms, batch study was conducted to find out the optimum adsorbent dosage, $\mathrm{pH}$, contact time, and adsorbate concentration.

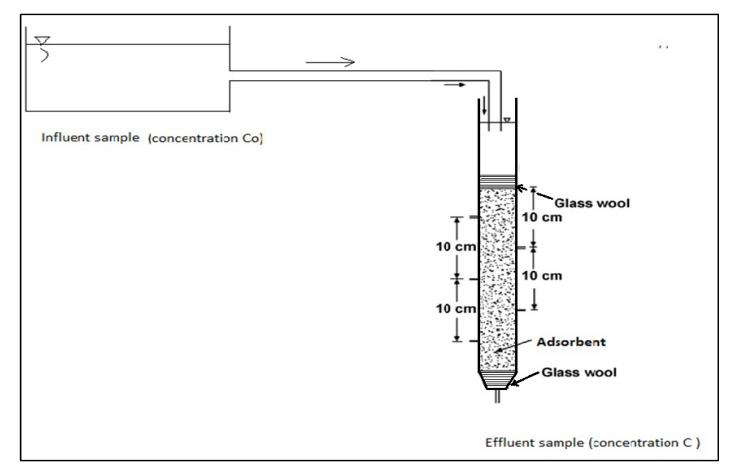

Fig.1: Experimental Setup for column study

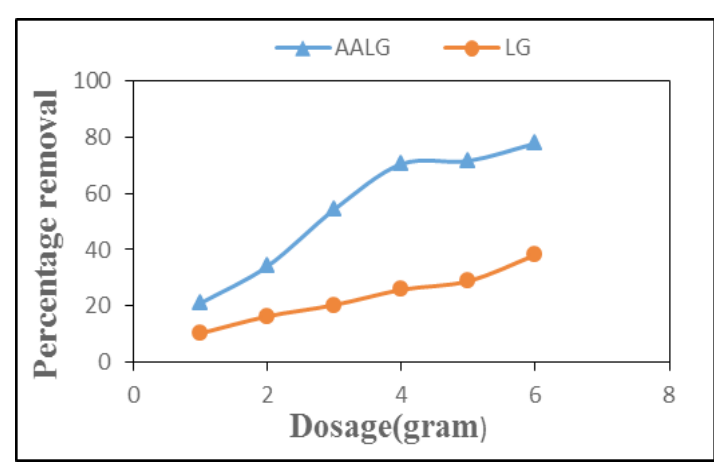

Fig. 2: Variation of percentage removal with dosage of LG and AALG 


\section{Effect of dosage LG and AALG}

The effect of adsorbent dosage on LG and $A A L G$ is as shown in Figure.2. Experimental studies were carried out in the room temperature with initial adsorbate concentration $10 \mathrm{mg} / \mathrm{L}$ using adsorbent dosage-1to $6 \mathrm{~g}$ at $\mathrm{pH} 7.0$ for $1 \mathrm{~h}$ contact time. The percentage removal increased with increase in adsorbent dosage. For the optimum dosage of $6 \mathrm{~g}$, the removal efficiency of both the adsorbents LG and AALG was found to be $38 \%$ and $78 \%$.

\section{Effect of pH for LG and AALG}

The effect of $\mathrm{pH}$ on $L G$ and AALG is as shown in Figure.3. Experimental studies were carried out in the room temperature with initial adsorbate concentration 10mg/L using adsorbent dosage-6g at $\mathrm{pH}-2$ to 8 for $1 \mathrm{~h}$ contact time. The adsorption behaviour with $\mathrm{pH}$ is different for LG and AALG. The removal efficiency of hexavalent chromium increased with increase in $\mathrm{pH}$ in case of AALG in contrast to the case of LG. Maximum removal efficiency of $78 \%$ was obtained for $\mathrm{pH}-7$ for AALG and $53 \%$ at $\mathrm{pH}-2$ for $L G$. The study attributed that AALG adsorbent is more effective than $L G$.

Table 3: Soil characteristics

\begin{tabular}{llcc}
\hline \multirow{2}{*}{$\begin{array}{l}\text { SI. } \\
\text { no }\end{array}$} & Soil characteristic & \multicolumn{2}{c}{ Value } \\
\cline { 3 - 4 } & & LG & AALG \\
\hline 1 & Silica (\%) & 50.7 & 56.4 \\
2 & Iron oxide $\left(\mathrm{Fe}_{2} \mathrm{O}_{3}\right)(\%)$ & 29.34 & 24.6 \\
3 & Alumina ( \% ) & 8.1 & 6.8 \\
4 & Organic carbon content (\%) & 0.29 & 0.06 \\
5 & Carbonate content (\%) & 4.5 & 1.3 \\
6 & pH $_{\text {ZPC }}$ & 5.95 & 4 \\
\hline
\end{tabular}

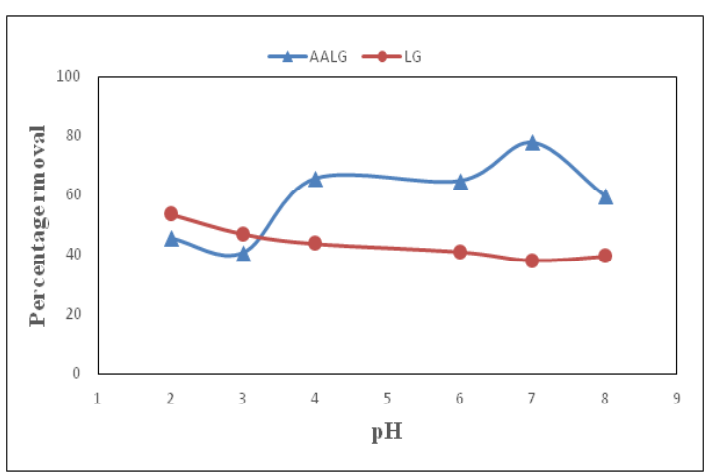

Fig. 3: Variation of percentage removal with $\mathrm{pH}$ for $L G$ and AALG

\section{Effect of contact time for LG and AALG}

The effect of contact time on removal efficiency $L G$ and AALG is as shown in Figures. 4. and 5. The percentage removal increased with increase in contact time and reached equilibrium after 2 hours. Equilibrium time increased by 1 hour than that of LG. The interfaces of $\mathrm{Cr}(\mathrm{VI})$ were fast initially, but the equilibrium was reached only after an appreciable length of time. Although $80 \%$ of maximum adsorption of $\mathrm{Cr}(\mathrm{VI})$ was attained within 30 min with AALG, the equilibrium could be attained only after $120 \mathrm{~min}$. Also from the graph it is evident that the equilibrium percentage removal was almost independent of initial adsorbate concentration.

\section{Effect of initial adsorbate concentration LG and AALG}

The effect of concentration on removal efficiency of $L G$ and AALG is as shown in Figure.6. It can be seen that the equilibrium percentage removal increased when initial chromium concentration was increased from $2.5 \mathrm{mg} / \mathrm{L}$ to $5 \mathrm{mg} / \mathrm{L}$ and thereafter the removal efficiency remained almost constant for concentrations up to $20 \mathrm{mg} / \mathrm{L}$ for AALG. The percentage removal obtained was higher than that obtained for LG for all concentrations. Almost $80 \%$ removal efficiency was obtained for adsorbate concentrations from $5 \mathrm{mg} / \mathrm{L}$ to $20 \mathrm{mg} / \mathrm{L}$. The increase in percentage removal upon AALG was lower than LG. In case of $2.5 \mathrm{mg} / \mathrm{L}$, the percentage removal was found to be $9.29 \%$ and at a higher initial adsorbent concentration of $20 \mathrm{mg} / \mathrm{L}, 34.04 \%$ removal efficiency was found with LG.

\section{Adsorption isotherms LG and AALG}

The equilibrium adsorption data obtained through batch adsorption studies were fitted into

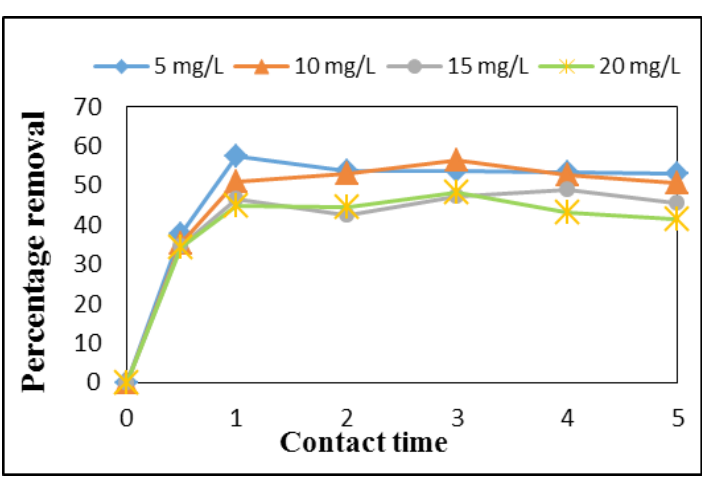

Fig. 4: Variation of percentage removal with contact time for LG 
two most commonly used adsorption isotherms Frendulich and Langmuir isotherms. The linearized isotherm plots are shown in Figure.7 and Figure. 8. The isotherm coefficients and correlation coefficients $\left(R^{2}\right)$ are given in table 4 . The correlation coefficient $\left(R^{2}\right)$ value for $L G$ was obtained as 0.997 and 0.950 for Freundlich and Langmuir isotherms respectively, which indicates the usability of both isotherm models to explain the adsorption behavior of $\mathrm{Cr}(\mathrm{VI})$. The $\mathrm{R}^{2}$ value of AALG for Freundlich and Langmuir isotherm obtained was 0.95 and 0.126 indicating the inability of the isotherm model to explain the adsorption behavior. The disagreement with the Langmuir model might be due to heterogeneity in adsorbent surface with resulting variation in adsorption energy.

\section{Column studies for LG and AALG}

For the column studies hexavalent chromium solution of known initial concentration $5 \mathrm{mg} / \mathrm{L}, 10 \mathrm{mg} / \mathrm{L}$ and $\mathrm{pH}=7$ was continuously fed at the top of the column bed at a fixed flow rate of $5 \mathrm{~mL} / \mathrm{min}$ for both LG and AALG. A plot of the ratio of effluent adsorbate concentration $(C)$ to the initial concentration $\left(C_{0}\right)$ against the time of flow $(t)$ yielded the breakthrough curve (BTC). Figure 9, depicts the breakthrough curves obtained for adsorbate concentrations $5 \mathrm{ppm}$ and $10 \mathrm{ppm}$ on $L G$ and $A A L G$. The $C / C_{0}$ value is found to increase with an increase in flow time for both the adsorbate concentrations which means that the amount of $\mathrm{Cr}$ $(\mathrm{VI})$ increased in effluent with the passage of time.

Table 4: Adsorption isotherm coefficients for LG and AALG

\begin{tabular}{|c|c|c|c|c|c|}
\hline \multicolumn{6}{|c|}{ LG } \\
\hline \multicolumn{3}{|c|}{ Freundlich } & \multicolumn{3}{|c|}{ Langmuir } \\
\hline$\overline{K_{f}}$ & $1 / n$ & $\overline{\mathrm{R}^{2}}$ & $\bar{a}$ & b & $\overline{\mathrm{R}^{2}}$ \\
\hline \multirow[t]{2}{*}{0.006} & 0.723 & 0.997 & 0.08 & 0.082 & 0.950 \\
\hline & \multicolumn{5}{|c|}{ AALG } \\
\hline \multicolumn{3}{|c|}{ Freundlich } & \multicolumn{3}{|c|}{ Langmuir } \\
\hline$\overline{\mathbf{K}_{f}}$ & $1 / n$ & $\overline{\mathrm{R}^{2}}$ & $\bar{a}$ & $b$ & $\overline{\mathrm{R}^{2}}$ \\
\hline 0.0133 & 0.895 & 0.95 & -0.00029 & $-3.6^{*} 10^{\wedge-6}$ & 0.126 \\
\hline
\end{tabular}

Table 5: Adsorption column performance for $L G$ and AALG

\begin{tabular}{|c|c|c|c|c|c|c|c|c|}
\hline \multirow[b]{2}{*}{$\begin{array}{l}C_{0} \\
(\mathrm{mg} / \mathrm{L})\end{array}$} & \multicolumn{4}{|c|}{ LG } & \multicolumn{4}{|c|}{ AALG } \\
\hline & $\begin{array}{c}q_{a d} \\
(\mathrm{mg})\end{array}$ & $\begin{array}{l}m_{\text {total }} \\
(\mathrm{mg})\end{array}$ & $\begin{array}{c}R \\
(\%)\end{array}$ & $\underset{(\mathrm{mg} / \mathrm{g})}{\mathrm{q}_{\mathrm{eq}}}$ & $\begin{array}{c}\overline{q_{\mathrm{ad}}} \\
(\mathrm{mg})\end{array}$ & $\begin{array}{l}\mathrm{m}_{\text {total }} \\
(\mathrm{mg})\end{array}$ & $\begin{array}{c}R \\
(\%)\end{array}$ & $\underset{(\mathrm{mg} / \mathrm{g})}{\mathrm{q}_{\mathrm{eq}}}$ \\
\hline 5 & 0.82 & 2.2 & 37.2 & 0.0045 & 3.062 & 3.75 & 81.6 & 0.0170 \\
\hline 10 & 0.95 & 2.8 & 34.0 & 0.0052 & 5.575 & 7.5 & 74.3 & 0.031 \\
\hline
\end{tabular}

$\mathrm{q}_{\mathrm{ad}=}$ total adsorbate adsorbed in the column; $\mathrm{m}_{\text {total }}=$ total adsorbate passed through column; $q_{e q}=$ adsorbate adsorbed in $1 \mathrm{~g}$ of adsorbent; $(R \%)=$ overall removal

Table 6: Adsorption isotherm coefficients for ferric ion

\begin{tabular}{lllllll}
\hline \multicolumn{2}{l}{ Frendulich isotherm constants } & & & \multicolumn{3}{c}{ Langmuir isotherms constants } \\
\cline { 5 - 7 } $\mathbf{K}_{\mathrm{f}}$ & $\mathbf{1 / n}$ & $\mathbf{R}^{2}$ & & $\mathbf{a}$ & $\mathbf{b}$ & $\mathbf{R}^{2}$ \\
\hline 0.22 & -0.282 & 0.453 & & 0.1658 & 0.922 & 0.901 \\
\hline
\end{tabular}


The breakthrough point of the column was taken as the point when $\mathrm{C} / \mathrm{C}$ value becomes 0.8 . The adsorption column achieved breakthrough at $76 \mathrm{~min}$ and $42 \mathrm{~min}$ for $5 \mathrm{mg} / \mathrm{l}$ and $10 \mathrm{mg} / \mathrm{l}$, respectively i.e. the column achieved breakthrough at a faster rate for higher concentration.

The breakthrough curves obtained for AALG were flatter than that obtained for $R L$. No considerable increase was observed in $\mathrm{C} / \mathrm{C}_{0}$ value for AALG for the first 20 min of flow, which indicates that there was no sudden decrease in effluent quality with the passage of time as in the case of $R L$. The column achieved breakpoint at $150 \mathrm{~min}$ and $130 \mathrm{~min}$ for $5 \mathrm{mg} / \mathrm{l}$ and $10 \mathrm{mg} / \mathrm{l}$ respectively. An increase in breakpoint time by $74 \mathrm{~min}$ with respect to $5 \mathrm{mg} / \mathrm{l}$ and $88 \mathrm{~min}$ for $10 \mathrm{mg} / \mathrm{l}$ was observed when compared to LG. Table 5. The total percentage removal and adsorption capacity obtained in column studies for LG and AALG.

It is evident that the percentage removal $(\mathrm{R} \%)$ and adsorption capacity $\left(\mathrm{q}_{\mathrm{eq}}\right)$ increased considerably for AALG. An increase in the percentage removal of $44.39 \%$ was obtained for $5 \mathrm{mg} / \mathrm{l}$ and that about $40.27 \%$ was obtained for $10 \mathrm{mg} / \mathrm{l}$. The concentration difference between $\mathrm{Cr}(\mathrm{VI})$ over the

Table 7: Adsorption column performance for ferric ions

\begin{tabular}{lcccc}
\hline $\begin{array}{l}\mathrm{C}_{\mathrm{o}} \\
(\mathrm{ppm})\end{array}$ & $\begin{array}{c}\mathrm{q}_{\mathrm{ad}} \\
(\mathbf{m g})\end{array}$ & $\begin{array}{c}\mathrm{m}_{\mathrm{total}} \\
(\mathbf{m g})\end{array}$ & $\begin{array}{c}\mathbf{R} \\
(\%)\end{array}$ & $\begin{array}{c}\mathrm{q}_{\mathrm{eq}} \\
(\mathbf{m g} / \mathrm{g})\end{array}$ \\
\hline 2.5 & 3.42 & 5.5 & 62.27 & 0.019 \\
\hline
\end{tabular}

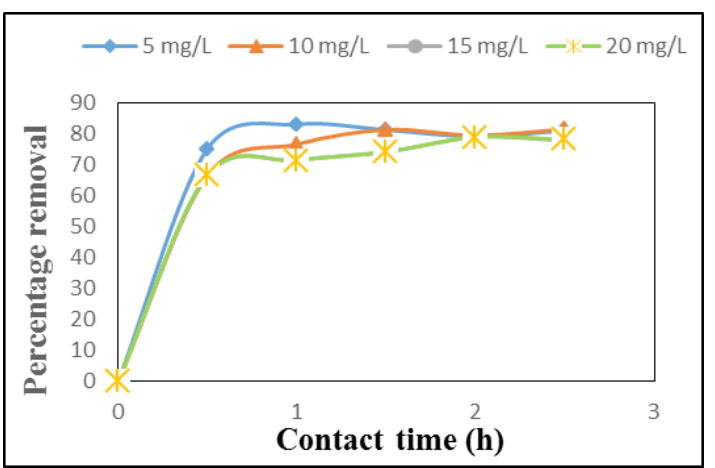

Fig. 5: Variation of percentage removal with contact time for AALG adsorbent surface with that the solution is the driving force for the adsorption which explains the reason for the decrease in break through time with incremental of initial metal concentration. Higher amount of metals can adsorbed by providing bigger driving force for mass transfer process provided through high initial concentration of adsorbate ions. Increase in diffusion coefficient is due to the difference in higher concentration where in quick transport of metals from solution onto adsorbent take place.

\section{Adsorption Studies of Ferric lons on LG- Batch Studies}

\section{Adsorption batch studies on LG}

Adsorption studies of Fe (III) ions were conducted on LG. Batch studies were done at a constant $\mathrm{pH}$ of 3 . The increase in $\mathrm{pH}$ beyond 3 led to the precipitation of ferric hydroxide due to reaction with $\mathrm{NaOH}$ used to adjust $\mathrm{pH}$.

\section{Effect of laterite dosage}

Effect of adsorbent dosage for removal of ferric ion is shown in Figure.10 Adsorbent dosage varied from 0.5 to $3 \mathrm{~g}$ with $\mathrm{pH}-3$, initial concentration $10 \mathrm{mg} / \mathrm{l}$, contact time 60min. The Percentage removal increased with increase in laterite dosage. When the optimum dosage was $2 \mathrm{~g}$, the removal efficiency LG was found to be $58 \%$, afterwards it remained almost constant. Therefore laterite dosage of $2 \mathrm{~g}$ was used up as optimum dosage and further adsorption studies were performed with the same adsorbent dosage.

\section{Effect of contact time}

Effect of contact time for removal of ferric ion is as shown in Figure.11. Contact time varied from

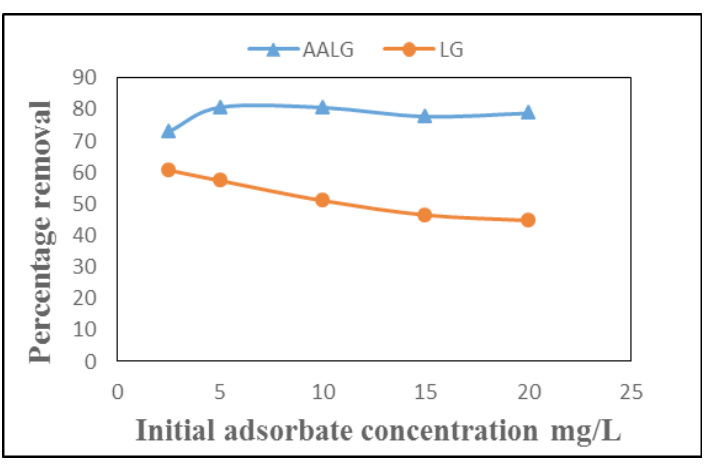

Fig. 6: Variation of percentage removal with initial concentration for $L G$ and AALG 
$15 \mathrm{~min}-60 \mathrm{~min}$, initial concentration $5 \mathrm{mg} / \mathrm{L}$ to $20 \mathrm{mg} / \mathrm{L}$ $\mathrm{pH}-3$, dosage- $2 \mathrm{~g}$. . Initially percentage removal increased with increase in contact time. This trend continued for a contact time of $45 \mathrm{~min}$, afterwards the percentage removal remained almost constant indicating that the system attained equilibrium. The equilibrium contact time was 45 min irrespective of the initial adsorbate concentration

\section{Effect of initial adsorbate concentration}

Effect of initial adsorbate concentration for removal of ferric ion is as shown in Figure.12. Initial
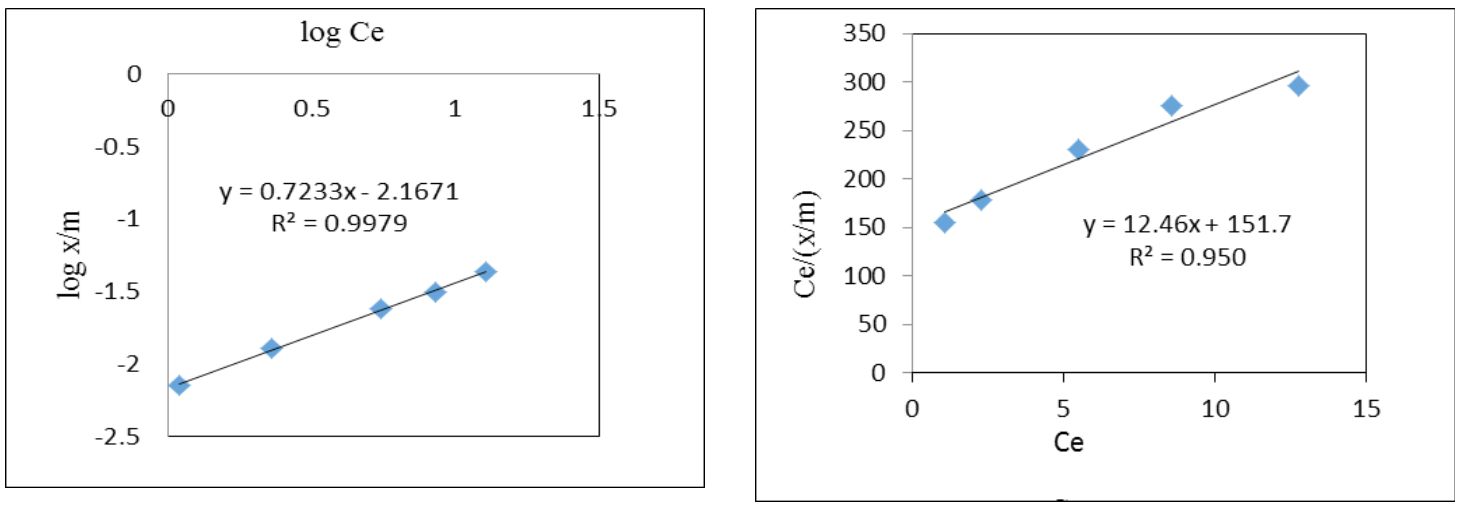

Fig. 7: Freundlich and Langmuir isotherm for adsorption of chromium onto LG
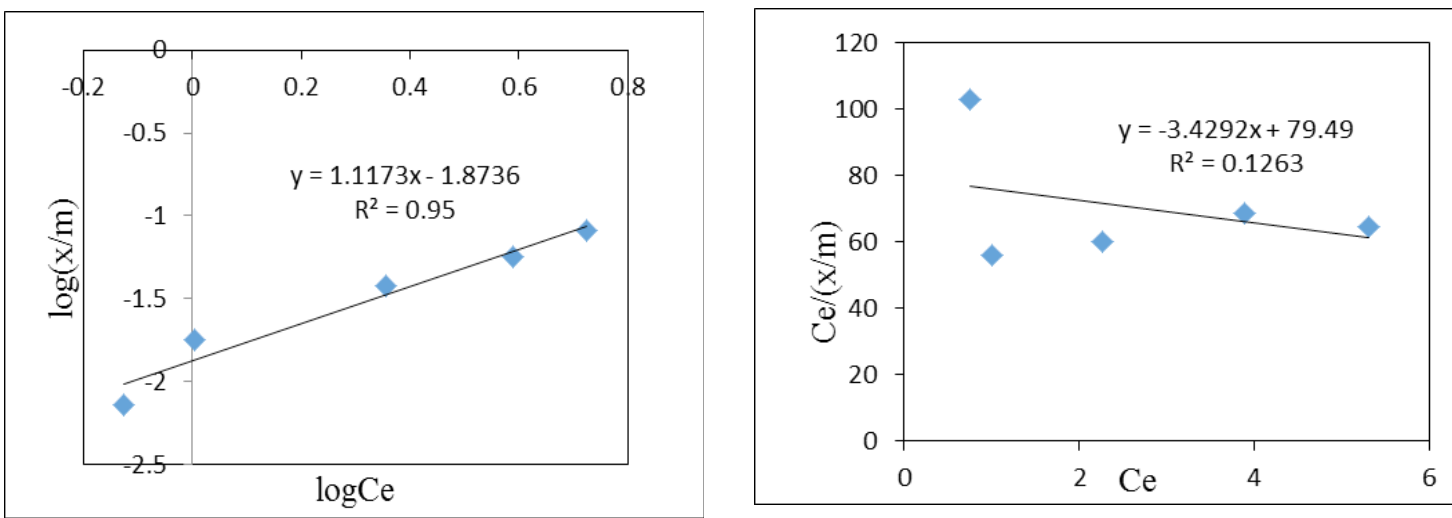

Fig. 8: Freundlich and Langmuir isotherm for adsorption of chromium onto AALG.

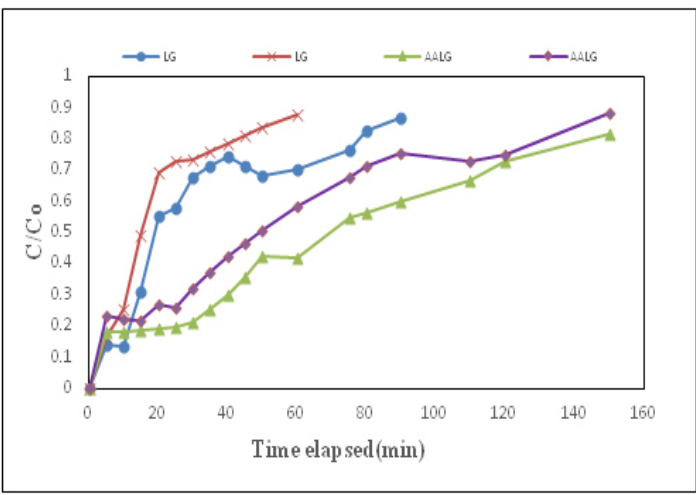

Fig. 9: Column breakthrough curve for LG and AALG.

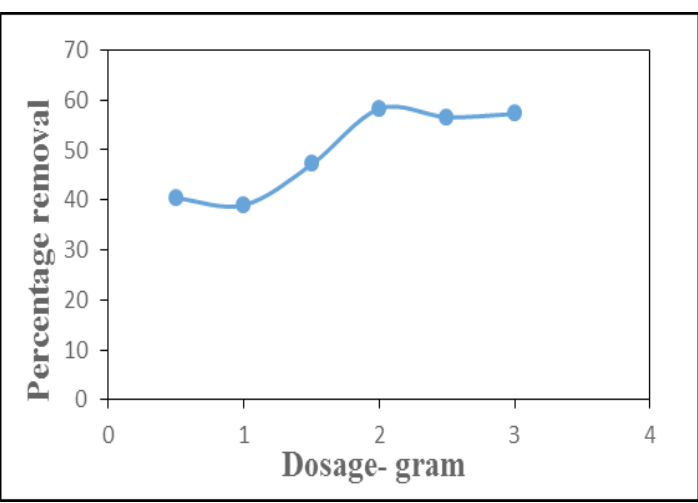

Fig.10: Effect of adsorbent dosage on percentage removal 
adsorbate concentration varied from $2.5 \mathrm{mg} / \mathrm{l}$ to $20 \mathrm{mg} / \mathrm{l}, \mathrm{pH}-3$, dosage-2g, and contact time-45min. Percentage removal was found to decrease with increase in initial ferric ion concentration. With an increase in adsorbate concentration of $2.5 \mathrm{mg} / \mathrm{l}$ to $20 \mathrm{mg} / \mathrm{l}$, the percentage removal decreased by $50.43 \%$. Maximum equilibrium percentage removal of $84.5 \%$ was obtained for ferric ion concentration of $2.5 \mathrm{mg} / \mathrm{l}$.

\section{Adsorption isotherms}

The equilibrium adsorption data obtained from batch studies of ferric ions was fitted into Freundlich and Langmuir isotherms and the plots obtained are as shown in Figure.13.. The isotherm coefficients and correlation coefficients are given in table. 6 . It can be observed that the Langmuir model fits into the adsorption data while Freundlich model fails in the same. Further the correlation coefficient obtained for Freundlich isotherm is 0.453 and indicates a poor correlation between the data and isotherm model.

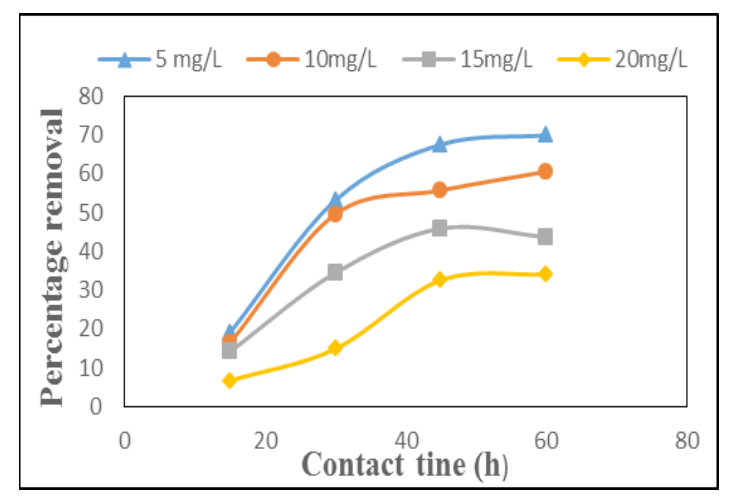

Fig.11: Variation in percentage removal with contact time

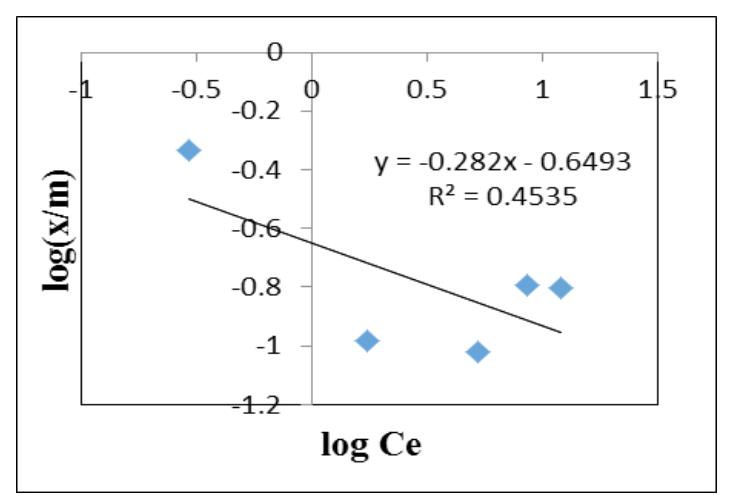

Adsorption studies of ferric ions on laterite soil grains- column studies

In column studies ferric ion solutions of known initial concentration $2.5 \mathrm{mg} / \mathrm{l}$, and $\mathrm{pH}-3$ was continuously fed at the top of the column bed at a fixed flow rate of $5 \mathrm{ml} / \mathrm{min}$. The breakthrough curve obtained for adsorbate concentration of $2.5 \mathrm{mg} / \mathrm{l}$ is as shown in Figure.14. The $\mathrm{C} / \mathrm{C}_{0}$ value was around 0.1 , at the start of the experiment then it gradually reduced up to 0.002 . After $90 \mathrm{~min} \mathrm{C} / \mathrm{C}_{0}$ began to increase, indicating the increasing quantity of ferric ion in the effluent. The column breakthrough was obtained after a flow period of $420 \mathrm{~min}$. The reason may be the decrease in adsorption efficiency with increased adsorbate concentration or maybe no availability of adsorption sites in the column due to complete saturation. Table.7. gives the total percentage removal and adsorption capacity for $2.5 \mathrm{mg} / \mathrm{l}$ concentration.

The total percentage removal obtained for $2.5 \mathrm{mg} / \mathrm{l}$ was $62.27 \%$, which is lesser than that

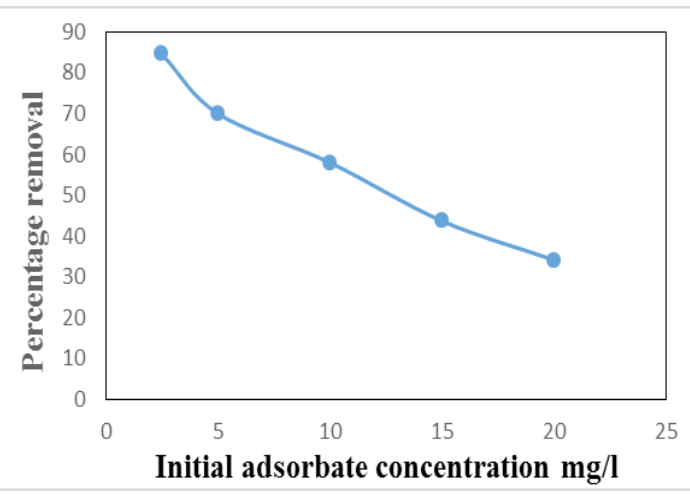

Fig.12: Variation in percentage removal with initial adsorbate concentration

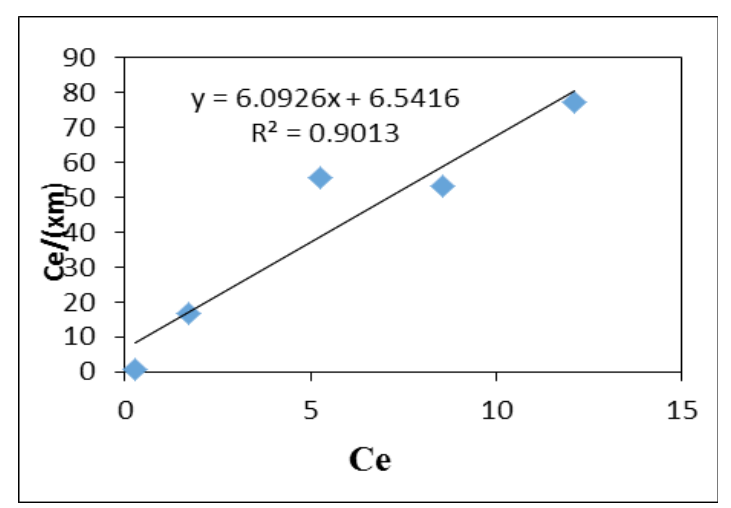

Fig.13: Freundlich and Langmuir isotherm for adsorption of ferric ion onto LG 


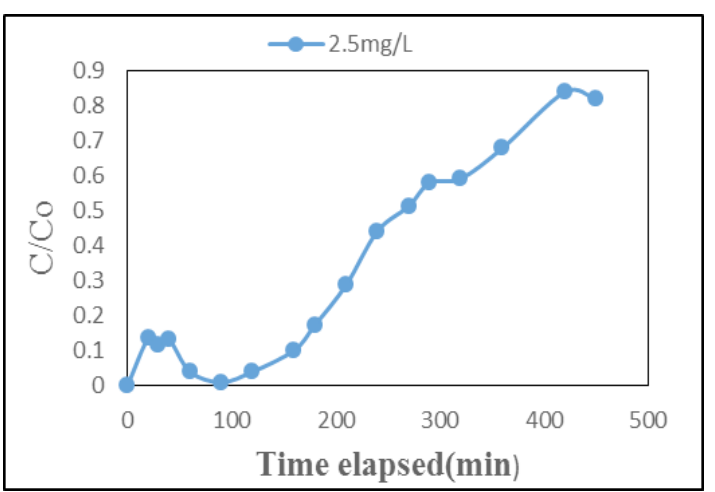

Fig.14: Column breakthrough curve for ferric ion

obtained in batch studies, similar to the case of $\mathrm{Cr}$ (VI). In the case of Fe (III), adsorption in batch mode was found to be more efficient than that in column mode.

\section{CONCLUSION}

In the present study removal of $\mathrm{Cr}(\mathrm{VI})$ and Fe (III) from aqueous solutions was achieved using $L G$ and AALG as an adsorbent. In batch study the maximum removal efficiency of $L G$ and AALG for removal of $\mathrm{Cr}(\mathrm{VI})$ were found to be $48 \%$ and $78 \%$ with initial adsorbent dose $2 \mathrm{~g} / \mathrm{l}, \mathrm{pH}-7$ and contact time $60 \mathrm{~min}$, respectively. The adsorption of $\mathrm{Cr}$ (VI) and Fe (III) was evaluated by the Langmuir, Freundlich isotherm models. The adsorption of $\mathrm{Cr}$ (VI) on LG followed both Freundlich and Langmuir isotherm models, while adsorption on AALG followed only the Freundlich model. The adsorption behavior of ferric ion showed deviation from Freundlich model, while it was found to agree with Langmuir model. The $\mathrm{Cr}$ (VI) removal efficiency obtained from laterite column was lesser than the efficiency obtained in batch mode. The removal efficiency of laterite column decreased with increase in adsorbate concentration. The LG column achieved breakpoint faster than AALG, indicating than AALG can accomplish removal for a larger time period than that of LG column. The column removal efficiency of chromium and ferric ion was found lesser than that of removal obtained by batch mode. From the whole work it can be concluded that laterite grains of size in between $0.6 \mathrm{~mm}$ and $1.18 \mathrm{~mm}$ are less efficient in removal of $\mathrm{Cr}(\mathrm{VI})$ from aqueous solutions but are efficient adsorbents of Fe (III) for low adsorbate concentrations. AALG can considerably increase the removal efficiency and can act as an efficient adsorbent in both batch and column mode.

\section{REFRENCES}

1. Ajmal, Mohammad, Rafaqat Ali Khan Rao, and Bilquees Ara Siddiqui. "Studies on Removal and Recovery of $\mathrm{Cr}(\mathrm{VI})$ from Electroplating Wastes." Water Research 30: 1478-82 (1996).

2. Chand, SHRI, V. K. Agarwal, and PAVAN Kumar. "Removal of Hexavalent Chromium from Wastewater by Adsorption." Indian Journal of Environmental Health 36: 151-58 (1994). Retrieved (http://cat.inist.fr/?aModel $\mathrm{e}=$ afficheN\&cpsidt=3658428).

3. Kousalya, G. N., Muniyappan Rajiv Gandhi, and S. Meenakshi. "Preparation of Modified Chitin for the Removal of Chromium(VI)." Bioremediation Journal 14: 208-18 (2010).

4. Maiti, Abhijit, Jayanta Kumar Basu, and Sirshendu De. "Removal of Arsenic from Synthetic and Natural Groundwater Using Acid-Activated Laterite." Environmental
Progress and Sustainable Energy 29: 457-70 (2010).

5. Maiti, Abhijit, Barun Kumar Thakur, Jayanta Kumar Basu, and Sirshendu De. "Comparison of Treated Laterite as Arsenic Adsorbent from Different Locations and Performance of Best Filter under Field Conditions." Journal of Hazardous Materials 262: 1176-86 (2013).

6. Maji, Sanjoy K., Anjali Pal, and Tarasankar Pal. "Arsenic Removal from Aqueous Solutions by Adsorption on Laterite Soil." Journal of environmental science and health. Part $A$, Toxic/hazardous substances \& environmental engineering 42: 453-62 (2007).

7. Maji, Sanjoy Kumar, Anjali Pal, and Tarasankar Pal. "Arsenic Removal from Real-Life Groundwater by Adsorption on Laterite Soil." Journal of Hazardous Materials 151: 811-20 (2008). 
8. Maji, Sanjoy Kumar, Anjali Pal, Tarasankar Pal, and Asok Adak. "Modeling and Fixed Bed Column Adsorption of As(III) on Laterite Soil." Separation and Purification Technology 56: 284-90 (2007).

9. Mohan, Dinesh and Kunwar P. Singh. "Singleand Multi-Component Adsorption of Cadmium and Zinc Using Activated Carbon Derived from Bagasse-an Agricultural Waste." Water research 36: 2304-18 (2002).

10. Owlad, Mojdeh, Mohamed Kheireddine Aroua, Wan Ashri Wan Daud, and Saeid Baroutian."Removal of Hexavalent ChromiumContaminated Water and Wastewater: A Review." Water, Air, and Soil Pollution 200 (1-4): 59-77 (2008). Retrieved November 11, 2014 (http://link.springer.com/10.1007/ s11270-008-9893-7).

11. Reymond, J. P. and F. Kolenda. "Estimation of the Point of Zero Charge of Simple and Mixed Oxides by Mass Titration." Pp. 30-36 in Powder Technology, 103 (1999).

12. Rowell, D. L. Soil Science: Methods \& Applications. Longman Scientific and Technical (1994).

13. Sahu, J. N., S. Agarwal, B. C. Meikap, and M. N. Biswas. "Performance of a Modified MultiStage Bubble Column Reactor for lead(II) and Biological Oxygen Demand Removal from Wastewater Using Activated Rice Husk." Journal of Hazardous Materials 161: 317-24 (2009).

14. Sarkar, Mitali, Aparna Banerjee, Partha Pratim Pramanick, and Asit R. Sarkar. "Use of Laterite for the Removal of Fluoride from Contaminated Drinking Water." Journal of Colloid and Interface Science 302: 432-41 (2006).

15. Soil Engineering and Rock Mechanics Sectional Committee, BDC 23. 1982. Indian Standard METHODS OF TEST FOR SOILS (IS/ : 2720 ( Part XXV ) - 1982). Retrieved (https://law.resource.org/pub/in/bis/S03/ is.2720.25.1982.pdf).

16. Soil Engineering Sectional Committee, BOC 23. 1972. Indian Standard METHODS OF TEST FOR SOILS (IS) : 2720 (Part XXII ) - 1972 (Reaffirmed 2010)). Retrieved (https://law.resource.org/pub/in/bis/S03/ is.2720.22.1972.pdf).

17. Srinivasa Rao, Karanam, Shashi Anand, and Paladugu Venkateswarlu. 2010. "Adsorption of cadmium(II) Ions from Aqueous Solution by Tectona Grandis L.F. (teak Leaves Powder)." BioResources 5:438-54.

18. United States Environment Protection Agency. 2004. "SW-846 On-Line." P. 3500 in Test Methods for Evaluating Solid Waste, Physical/Chemical Methods. Retrieved (http:// www.epa.gov/osw/hazard/testmethods/ sw846/pdfs/9045d.pdf).

19. Wagner, C. D., H. L. Clever, and E. D. Peters. 1947. "Evaluation of Ferrous Thiocyanate Colorimetric Method." Analytical Chemistry 19(12):980-82. Retrieved January 15, 2015 (http://pubs.acs.org/doi/abs/10.1021/ ac60012a011). 